\title{
Article \\ The Impact of HVAC on the Development of Autonomous and Electric Vehicle Concepts
}

\author{
Adrian König ${ }^{1, * \mathbb{C}}$, Sebastian Mayer ${ }^{1}$, Lorenzo Nicoletti $^{1}{ }^{10}$, Stephan Tumphart $^{2}$ and Markus Lienkamp $^{1}$ \\ 1 Institute of Automotive Technology, Technical University of Munich, Boltzmannstraße 15, \\ 85748 Garching, Germany; ga96bup@mytum.de (S.M.); lorenzo.nicoletti@tum.de (L.N.); \\ lienkamp@tum.de (M.L.) \\ 2 Magna Powertrain, Engineering Center Steyr, 4300 St. Valentin, Austria; Stephan.Tumphart@magna.com \\ * Correspondence: adrian.koenig@tum.de; Tel.: +49-89-289-10497
}

check for updates

Citation: König, A.; Mayer, S.; Nicoletti, L.; Tumphart, S.; Lienkamp, M. The Impact of HVAC on the Development of Autonomous and Electric Vehicle Concepts. Energies 2022, 15, 441. https://doi.org/ $10.3390 /$ en15020441

Academic Editor: Muhammad Aziz

Received: 2 December 2021

Accepted: 6 January 2022

Published: 9 January 2022

Publisher's Note: MDPI stays neutral with regard to jurisdictional claims in published maps and institutional affiliations.

Copyright: (C) 2022 by the authors. Licensee MDPI, Basel, Switzerland. This article is an open access article distributed under the terms and conditions of the Creative Commons Attribution (CC BY) license (https:// creativecommons.org/licenses/by/ $4.0 /)$.

\begin{abstract}
Automation and electrification are changing vehicles and mobility. Whereas electrification is mainly changing the powertrain, automation enables the rethinking of the vehicle and its applications. The actual driving range is an important requirement for the design of automated and electric vehicles, especially if they are part of a fleet. To size the battery accordingly, not only the consumption of the powertrain has to be estimated, but also that of the auxiliary users. Heating Ventilation and Air Conditioning (HVAC) is one of the biggest auxiliary consumers. Thus, a variable HVAC model for vehicles with electric powertrain was developed to estimate the consumption depending on vehicle size and weather scenario. After integrating the model into a tool for autonomous and electric vehicle concept development, various vehicle concepts were simulated in different weather scenarios and driving cycles with the HVAC consumption considered for battery sizing. The results indicate that the battery must be resized significantly depending on the weather scenario to achieve the same driving ranges. Furthermore, the percentage of HVAC consumption is in some cases higher than that of the powertrain for urban driving cycles, due to lower average speeds. Thus, the HVAC and its energy demand should especially be considered in the development of autonomous and electric vehicles that are primarily used in cities.
\end{abstract}

Keywords: battery electric vehicles; vehicle concept; autonomous; HVAC; auxiliary; WLTP; optimization

\section{Introduction}

The trend towards sustainable and automated mobility is currently changing the automotive industry [1]. While automation still faces hurdles in terms of legislation [2] (p. 4), numerous governments already support the sale of battery electric vehicles (BEVs) by introducing subsidies or increasing the taxation rate for vehicles with higher $\mathrm{CO}_{2}$ emissions [3] (p. 2). As a consequence, the share of new registrations of BEVs is rising and reached $6.2 \%$ in the European Union in 2020 [4]. However, BEVs still have problems with low ranges and high battery costs [5].

Despite the mentioned problems, automation promises a lot of advantages and changes to mobility. However, its potential is heavily dependent on its applications. Private Autonomous Vehicles (AVs) will continue to be oversized in most cases, to completely cover the mobility demand of a single person [6] (p. 580). However, AVs used in combination with new business models, such as ridesharing, will have their full saving potentials when they are the right size. Designing an AV fleet, for example for $99 \%$ instead of $99.9 \%$ of car trips in Germany, reduces the required range from $475 \mathrm{~km}$ to $135 \mathrm{~km}$ [6] (p. 580). In order to derive the battery size from the range of such a fleet vehicle, both the consumption of the powertrain and also of the auxiliary consumers (e.g., air conditioning) must be considered [7] (p. 142).

Up until now, auxiliary power consumption played a minor role in vehicle development. It was not considered since it is not part of the consumption calculation using driving 
cycles, such as the WLTP [8] (p. 30). However, since BEVs are more sensitive to increased auxiliary power due to the higher mass and volume of the battery [9] (p. 17), the real-world range deviates significantly from the range provided by the manufacturers. This especially occurs in cold or warm conditions due to the heating, ventilation, and air conditioning (HVAC) [10] (p. 423).

As described, the range of BEVs is highly sensitive to HVAC and knowledge of the range is, in turn, essential for the development and fleet planning of AVs. Consequently, auxiliary users and their energy demand are crucial for battery electric AVs. In addition to the HVAC, the automation system is considered as a second large auxiliary consumer for AVs. It consists of sensors and computers, which can lead to an increase in electricity consumption. Gawron [11] estimates an increase during the use of the vehicle between around $2 \%$ and $15 \%$, depending on the sensor set. Because there is still a lot of discussion about the correct sensor setup in industry and science and its energy consumption, mainly the HVAC system is considered in the scope of this paper.

In the following, we present a method to consider the HVAC system in the development of AVs (Figure 1). In this paper, we only consider battery electric AVs, although they could be equipped with other powertrain technologies. First, we describe the state of the art regarding cabin and HVAC models and vehicle concept development and derive the research gap (Section 2). Thereafter, we formulate requirements for the cabin and HVAC model and describe its design (Section 3.1). After validating the model with measured real-world data (Section 4), we develop a regression model (Section 5) to reduce computing time to allow the results to be used by the other researchers without needing any specific software. In parallel, we present the Autonomous Vehicle Concept Development Tool (AuVeCoDe), which supports the development of vehicle concepts in the early development phase. Using this tool, we show the impact of the HVAC system on different battery electric $\mathrm{AVs}$ (Section 6) as an example.

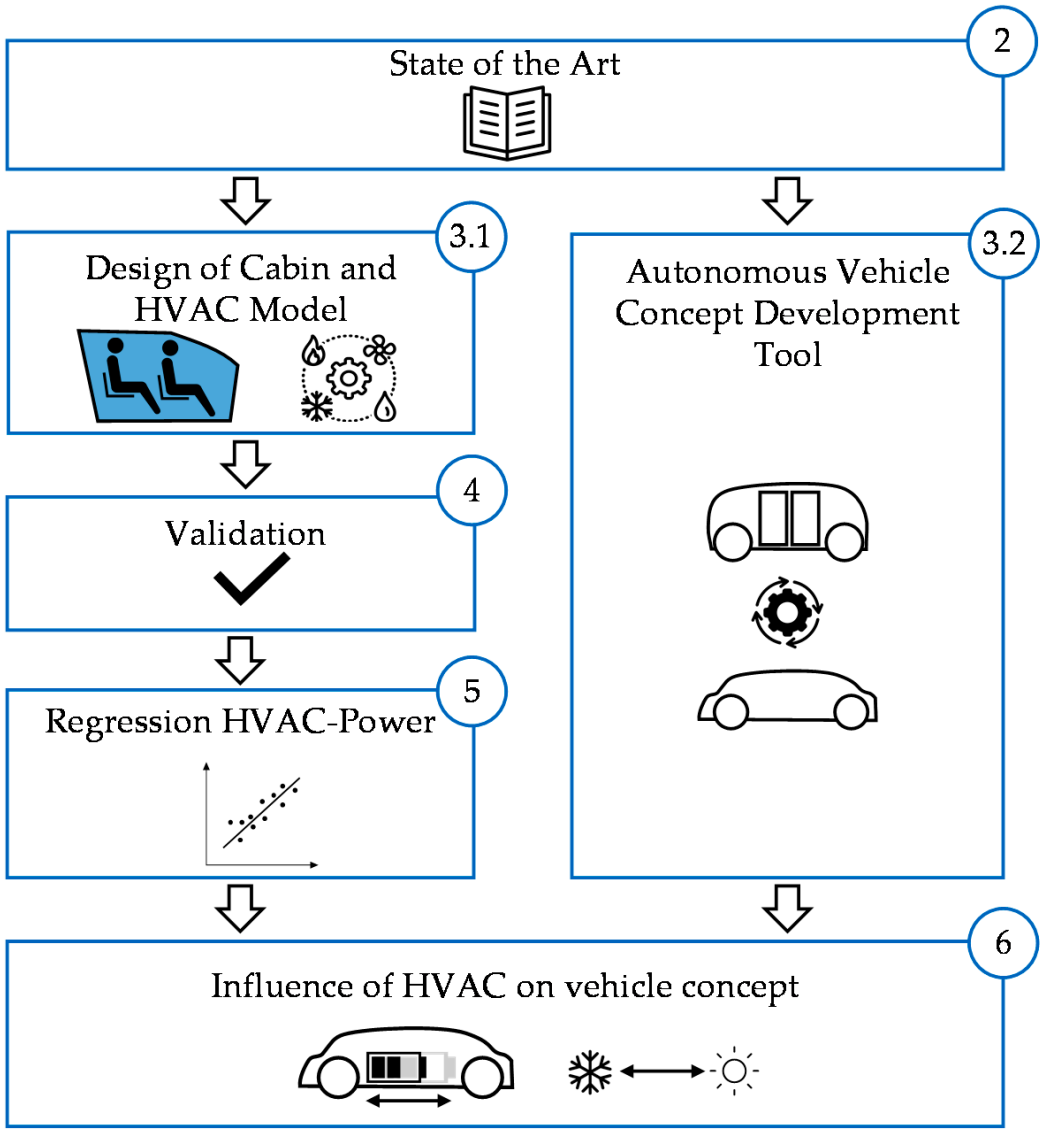

Figure 1. Structure of presented paper. 


\section{State of the Art}

Simulation models are needed to estimate the energy demand of HVAC systems during operation in the early development phase. For this scope, vehicle concepts are virtually developed to find optimal solutions before building expensive hardware prototypes (Section 2.1). In this process, thousands of possible vehicle configurations can be simulated to find the best combination. Those configurations include various sizes and shapes of the vehicle, which is why all models, including an HVAC model, have to be parametric.

Therefore, we first analyze the current state of the art for modeling the vehicle HVAC system (Section 2.2). Then, we evaluate whether an existing model is suitable for vehicle concept development. After evaluating the different approaches, we formulate the research gap (Section 2.3).

\subsection{Vehicle Concept Development}

Simplified concepts are initially used in the early development phase of a vehicle, to define the most important parameters for the subsequent steps. The vehicle concept process was established in order to iteratively find optimal solutions during this phase and avoid expensive changes in the later phases [1] (p. 1). Numerous vehicle parameters can be varied in the search for good solutions. Nicoletti et al. [12] (p. 1) describe the importance of those parameters and the need to define them to avoid late and expensive changes. They also highlight the problem of new technologies, such as electrification of the powertrain, creating the challenge of finding parameters without having any predecessor vehicle.

To overcome the problem of not having parameters from predecessor vehicles, several methodologies were developed to achieve optimal sets of parameters for vehicle concepts right from the start. Most of these methodologies consider electrification as new technology $[13,14]$. Since, to our knowledge, no methodology for concept design optimization of autonomous vehicles exists [1] (p. 6), we adapt the existing ones [15]. The consideration of the auxiliary consumers is an important part of this, because, as mentioned above, their consumption can account for a high proportion of the total consumption [15]. This is especially due to the higher auxiliary power consumption of autonomous vehicles. Furthermore, Schockenhoff [16] points out that autonomous vehicles also need an adaption of the concept development process. Therefore, we also ensure that our methodology is applicable to new versions of the process.

\subsection{HVAC Models}

HVAC models can be divided into cabin models and models of the HVAC system around the cabin. Wagner [17] describes four different cabin modeling types that can be used for the HVAC simulation:

- $\quad$ Empirical models (e.g., climate control);

- $\quad$ Single zone models (e.g., concept design);

- Multi-zone models (e.g., design of vehicle cabin);

- Co-simulation (e.g., optimization).

Whereas the cabin model includes glazing, passengers, and other thermal masses, the HVAC system models include components of the heating and the cooling cycle, as well as the ventilation for the cabin and the condenser air. In the following, we provide an overview of the relevant work that considers either the cabin, the HVAC system, or both.

Al Faruque et al. [10,18] modeled the consumption of the HVAC system in conjunction with a BEV architecture and a battery management system. The authors investigated the impact of the HVAC performance on the vehicle's range and battery lifetime. The implementation is done in AMESim and ADVISOR. The cabin is modeled using the single volume method, and also considers the heat input due to solar radiation. The methodology neglects the heat dissipation of the occupants, the transmittance of the windows, and the cabin geometry. There is no modeling of the refrigeration cycle and its components. However, the model calculates the cooling and heating power consumption, as well as the power of the fan, using three equations with constant values for the efficiencies. 
Broglia et al. [19] present a simulation model to estimate the energy consumption for air conditioning of electric vehicles and its influence on the available range and the cabin temperature. The authors evaluate various technologies and their impact during the SFTPUS06 driving cycle and various ambient temperatures. In this context, the refrigeration cycle with the refrigerant R134a, an electrical PTC-heater, and the vehicle cabin are modeled using AMESim. The results show that the HVAC-System is responsible for an increase in energy consumption of around $30 \%$ at ambient temperatures between $-5{ }^{\circ} \mathrm{C}$ and $0{ }^{\circ} \mathrm{C}$. For cooling the vehicle cabin at ambient temperatures of $30^{\circ} \mathrm{C}$ and $35^{\circ} \mathrm{C}$, the simulations show an increase of approximately 5\%. A point of criticism is that the authors do not consider humidity.

Fritz $[20,21]$ presents a holistic tool for truck air conditioning, focusing on energy consumption and thermal comfort. In addition, the author deals with the development of a complete vehicle test rig. The simulation model consists of the following sub models: vehicle environment, powertrain, HVAC system, passenger compartment, and operation strategy. For the HVAC performance calculations, Fritz only refers to the performance of the compressor and blower, neglecting the condenser fan. An advantage of this method is the short computation time.

Ganesan et al. [22] develop a parametric HVAC model in Matlab/Simulink focusing on climate control studies. The HVAC system is modeled using look-up tables, characteristic curves, and differential equations. This approach includes a model of the vehicle cabin as one single volume, neglecting solar radiation and cabin geometry. A simplified vehicle model only considering the longitudinal motion of the car is integrated to simulate the impact of the HVAC system on the fuel economy. The authors estimate an increase in energy consumption of $25 \%$ when the HVAC system is switched on.

Jefferies et al. [23] model the air conditioning of an electric bus in the simulation environment Modelica. The authors investigate several air conditioning concepts based on their economic efficiency and energy consumption. For the HVAC performance calculation, the approach considers all relevant components. The simulations determine a range reduction of $15 \%$ by cooling the cabin on hot days. For heating, the electric PTC heater achieves a reduction of $39 \%$ and an R744 heat pump achieves $22 \%$.

Kiss et al. [24] describe the HVAC model CoolSim in Matlab/Simulink. This consists of a model of the refrigeration cycle and a simplified single-zone cabin model including all relevant heat flows but neglecting the cabin geometry. The authors model the individual components of the HVAC system using mathematical equations and lookup tables. In another work, Kiss et al. [25] extend the model with a cooling cycle, an electric heater, and a heat pump function. This enables the modeling of the entire thermal management of an electric vehicle. The SC03-cycle is used for illustrating the capabilities of the model.

Lajunen [26] presents a simulation model for air conditioning and thermal management of electric vehicles. In this context, the author models the cooling and heating system, as well as the heat flows of the vehicle cabin while neglecting its geometry parameters. The implementation is done in AMESim. Using different driving cycles, the approach analyzes the impact of the HVAC system on the driving range. A comparison is done between a heat pump, a PTC-heater, and a heat exchanger for heat recovery. At moderate temperatures, the use of the heat pump leads to a range increase between $6 \%$ and $22 \%$.

Lee et al. [27] present a transient thermal model of a vehicle cabin in combination with an HVAC model. The modeling of the components of the air conditioning is done in an F-chart. The authors analyze different refrigerants regarding their power consumption and Coefficient of Performance (COP). The simulations show that the refrigerant R1234yf yields the largest improvements. However, the model does not include heating systems. Validation of the cabin model shows a maximum deviation of the cabin temperature from the measured data of $5 \%$.

Nielsen et al. [28,29] simulate the energy consumption of a Volvo S60, modeling the HVAC system and the vehicle cabin. Furthermore, the approach considers the air handling unit as well as the engine and its cooling system. The implementation is done in GT- 
Suite and the interior cabin model consists of 28 volume units. Using Computational Fluid Dynamics (CFD) simulations, the heat and mass flows between the individual zones are calculated before the actual simulation. Nielsen et al. verify the simulation data with the measured performances in the New European Driving Cycle. The maximum deviation of the compressor performance is $59 \%$. The maximum deviation of the total HVAC performance is $13 \%$.

Sevilgen et al. [30] present an HVAC and cabin model in AMESim, focusing on the analysis cooling and heating process of the passenger compartment. In addition, the paper deals with the COP calculation of the two refrigerants, R134a and R1234yf, with the former getting a slightly better result. The authors describe the influence of solar radiation, the temperature inside the cabin, and various refrigerants on HVAC performance.

Song et al. [31] present a method for the development of HVAC systems for BEV, focusing on the energy consumption and the design of the heat exchanger in e-Thermal and SINDA/FLUINT. Furthermore, the authors simulate the influence of the HVAC system on the available battery capacity. The results show a reduction of $13 \%$ in the self-designed driving cycle, having an active air condition with various vehicle operating modes, including soaking, idle, and several vehicle speeds $(50,80$, and $110 \mathrm{~km} / \mathrm{h})$. This corresponds to a range of $42 \mathrm{~km}$.

Subiantoro et al. [32] model an HVAC system for electric vehicles in Matlab/Simulink, studying different measures to reduce energy consumption. The approach considers the compressor power and the COP of the HVAC system. However, the energy demand from blowers and the heating system are not considered. The simulations show that an increase of the set temperature inside the passenger compartment from $20^{\circ} \mathrm{C}$ to $24^{\circ} \mathrm{C}$ results in an energy saving of $22 \%$ and an increase of the COP of $13 \%$.

Torregrosa-Jaime et al. [33] model the HVAC system of an electric minibus in Matlab/Simulink, focusing on the design and optimization of the air conditioning. The approach calculates the HVAC energy consumption with various environmental conditions, considering all relevant component performances. The modeling of the refrigeration cycle is done with IMST-ART. For heating the passenger compartment the authors focus on the heat pump, neglecting PTC-heaters. In another paper, Torregrosa-Jaime et al. [34] detail the lumped parameter model for the passenger compartment. They consider all relevant heat flows using mathematical equations and distinguish between a driver and passenger zone. The research shows that solar radiation is responsible for up to $18-31 \%$ of the thermal load. In addition, the authors determine that the electrical auxiliary consumers contribute to the total energy consumption with a share of between 29 and $40 \%$, depending on the fan activation set point.

Valentina et al. [35] present a simulation model to estimate the energy consumption of the HVAC system for BEVs, including models for the battery and the passenger compartment, taking into consideration the thermal comfort of the users. Connecting this approach to the navigation system of the car allows for the calculation of the impact of the HVAC system on the range of the vehicle. This model is suitable for applications in real-time.

Zhang and Canova [36] model an HVAC system for ICEV in Matlab/Simulink. This model allows for the calculation of the dynamic pressure profiles of the two heat exchangers and the compressor power. However, the performance of the blowers and the heating system is neglected. Validation is performed on a vehicle test bench. The authors only validate the pressure curves at the two heat exchangers.

The previous section summarized the state of the art for HVAC models. In the next step, the different approaches are evaluated, and the following criteria are defined:

- HVAC performance: This category shows whether the model calculates the performance of the HVAC system. Full compliance $(\bullet)$ is achieved when the model considers the performance of all components. This includes the compressor, blower, condenser fan, and heating systems. Partial compliance (o) is when the model does not consider all components or uses a constant COP; 
- Modeling level HVAC: This category addresses the level of detail of the HVAC system and the refrigeration cycle. Full compliance $(\bullet)$ is when the authors model all components of the refrigeration cycle and the two-phase behavior of the refrigerant. The simulation environments AMESim and GT-Suite, for example, meet these requirements. Partial fulfillment ( $($ ) is achieved when the refrigeration cycle is modeled using numerical or empirical equations. This is the case with Matlab/Simulink;

- Modeling level cabin: This category addresses the level of detail of the passenger compartment. Complete fulfillment $(\bullet)$ is achieved if the model considers all relevant heat flows and the cabin geometry. This includes the size of the car, as well as the angle and area of the different windows. In addition, this should be done without the use of CFD simulations to enable use in the early concept phase. No method fulfills this category. A partial fulfillment ( $(\mathbf{)})$ is achieved if not all heat flows are considered or if the cabin geometry is neglected. If the approach does not include a model of the cabin, this category is not fulfilled $(\bigcirc)$;

- Validation: This category shows whether validation of the model is available. Full compliance $(\bullet)$ is achieved if validation of the thermal behavior of the cabin and the HVAC performance is available. Partial fulfillment $(\boldsymbol{(})$ is achieved when the authors validate only the thermal behavior or the performance. The model does not fulfill this requirement $(O)$ if there is no validation of the simulation model.

Table 1 shows the evaluation of the HVAC models using the defined categories. Only a few models fulfil at least two criteria. Especially the cabin models are, in most cases, not scalable and therefore cannot simulate different vehicle sizes. Since variable cabin sizes are needed for vehicle concept development, a new model must be created. Furthermore, low computing time was set as a requirement, due to the numerous simulations in the optimization process.

Table 1. Input parameter of the HVAC and cabin model.

\begin{tabular}{|c|c|c|c|c|c|}
\hline Authors & Year & $\begin{array}{c}\text { HVAC } \\
\text { Performance }\end{array}$ & $\begin{array}{c}\text { Modeling } \\
\text { Level HVAC }\end{array}$ & $\begin{array}{l}\text { Modeling } \\
\text { Level Cabin }\end{array}$ & Validation \\
\hline Al Faruque et al. $[10,18]$ & $2015 / 16$ & a & 0 & a & 0 \\
\hline Broglia et al. [19] & 2012 & - & - & - & 0 \\
\hline Fritz $[20,21]$ & 2014/15 & - & - & - & - \\
\hline Ganesan et al. [22] & 2018 & - & - & - & 0 \\
\hline Jefferies et al. [23] & 2015 & - & - & - & 0 \\
\hline Kiss et al. $[24,25]$ & 2013/15 & - & - & - & a \\
\hline Lajunen [26] & 2017 & - & - & - & 0 \\
\hline Lee et al. [27] & 2015 & - & - & - & 0 \\
\hline Nielsen et al. $[28,29]$ & 2014/15 & - & - & - & - \\
\hline Sevilgen et al. [30] & 2020 & - & - & - & - \\
\hline Song et al. [31] & 2015 & - & - & - & 0 \\
\hline Subiantoro et al. [32] & 2014 & - & - & - & 0 \\
\hline Torregrosa-Jaime et al. [33,34] & 2013/14 & - & - & - & - \\
\hline Valentina et al. [35] & 2014 & - & - & - & - \\
\hline Zhang and Canova [36] & 2013 & - & - & 0 & - \\
\hline
\end{tabular}

\subsection{Research Gap}

Auxiliary consumers, such as HVAC, are gaining importance for automated and electric vehicles. On the one hand, HVAC has a higher impact on the driving range of BEVs compared to vehicles with internal combustion engines due to the electric powertrain. On the other hand, AVs will have the highest potential when being sized correctly for specific applications, instead of being oversized to meet every possible application. To be sized for specific applications, the vehicle range has to be known for optimal route planning and vehicle distribution. Until now, the literature considers the loss of range due to rising energy consumption in hot and cold scenarios, which would then result in climate and location-dependent re-planning of the routes. As an example, the same vehicle 
might operate fewer hours per day without charging in cities with higher temperatures than in cities with moderate temperatures. Taking the increased energy consumption by HVAC into account already during the development phase, and thus adapting the battery size accordingly, has not yet been considered. However, this would help ensure that vehicles achieve the required range at the planned location of operation under prevailing climate conditions.

Engineers try to find optimal solutions for vehicle concepts in the early phase of development to avoid expensive iterations and quickly adapt to new technologies. During this process, the important vehicle parameters are varied in order to investigate as many combinations as possible. One parameter is the vehicle and interior size, which, in turn, has an influence on the HVAC consumption. Consequently, an HVAC consumption model with variable vehicle sizes as an input is required. However, most of the current approaches to modeling the HVAC system and its power consumption do not consider different vehicle geometries and the sizes of the passenger compartment. Thus, they are not suitable for the early conception of autonomous electric vehicles.

Therefore, in this paper, we develop a model for BEVs to estimate the HVAC consumption depending on the vehicle size. Since the computing time of the used simulation model is too high, we derive regressions as a meta model (Section 5). Lastly, we investigate how HVAC impacts battery electric AV concepts when it is already considered during development (Section 6). We thus use a tool for the concept development of autonomous, electric vehicles to show the impact of exemplary climate scenarios on vehicle dimensions.

\section{Modeling of the HVAC and Autonomous Vehicle Concepts}

As is usual with simulation, a compromise must be found between computing time and accuracy. Furthermore, the components of the model must be parameterized as accurately as possible in order to accurately represent the real system. The simulation software KULI [37] from Magna best meets the requirements and was therefore used to build up and validate our model. In the first step, we describe the used modeling approach for the vehicle cabin and the HVAC system (Section 3.1). The description of the tool for vehicle concept development, which is used for investigating the influence of HVAC on the vehicle design, will be the second step (Section 3.2).

\subsection{Modeling the Passenger Compartment and the HVAC System}

KULI offers holistic engineering support for the design of specific air conditioning components and the overall thermal management of vehicles [37]. This includes the refrigerant and cooling cycle, the thermal management of the powertrain and the battery, as well as the passenger compartment. This tool offers a simple model and an extended model for modeling the passenger compartment and the interior climate comfort. The former models the cabin as one volume with one homogeneous interior temperature. The extended model includes different zones with an individual temperature. CFD-Simulations are needed for calculating the heat and mass flows between the single zones. CFD models have their strength in the temperature distribution, which is needed for comfort assessment, for example. Since concept optimization normally calculates thousands of different variations of vehicles, computing time and an easy parameter variation were important requirements. Thus, the extended model of the passenger compartment is not suitable for the development of the vehicle concept. Furthermore, numerous simulations must be carried out to generate data points for the creation of the meta model (Section 5). Therefore, we decided to use the simple 1D-model for the cabin and HVAC system with one homogenous interior temperature.

All relevant heat flows, including the calculation of the heat entry caused by the solar radiation, were considered in the $1 \mathrm{D}$ model. In KULI, the position of the sun is defined by two angles: the vertical angle of the sun to the street and the angle to the $x$-axis of the car. The windows of the vehicle are defined by three angles: The angle of the front window / windshield $\alpha$, the side window $\beta$, and rear window $\gamma$ (Figure 2). KULI calculates 
the incoming heat on the glass areas using these angles and the area of the front, side, and rear windows. A coefficient of transmission calculates the partial heat that enters the interior of the passenger compartment through the window areas. Thus, the approach allows the analysis of the impact of different window areas and angles, as well as the sun's intensity and position. Different climate conditions and global locations (e.g., Munich or Singapore) can be modeled. Moreover, the size of the cabin influences the heat exchange with the ambient temperature. The larger the vehicles, the higher the amount of heat exchange, which in turn depends on the temperature difference between the cabin and the environment. These parameters influence the power of the HVAC system.

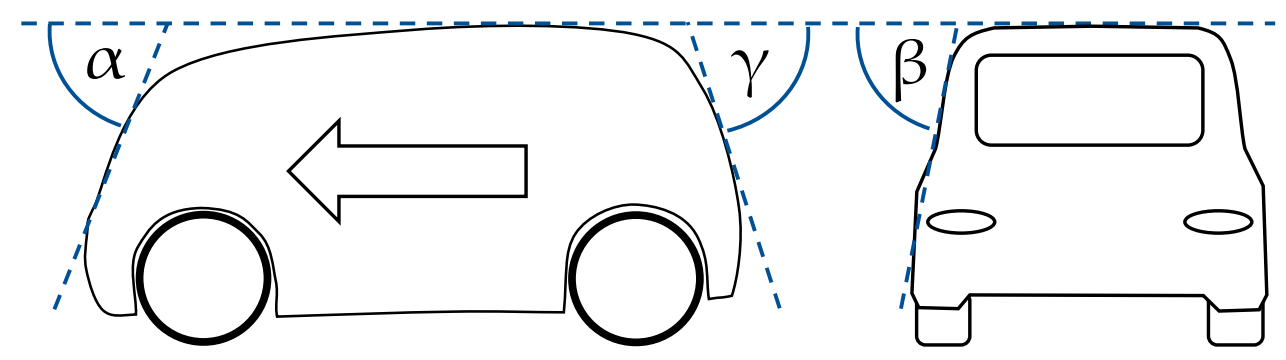

Figure 2. Definition of window angles in KULI.

For modeling the refrigerant circuit, KULI offers a user interface that enables adding and connecting different components, fans, and cooling circuits. The air conditioning model consists of modular independent component models based on geometric and measured data. Thus, the heat exchange between the fluids and the air flow as well as the performance of the whole air conditioning system and its dependencies can be analyzed during the design stage of the project. We model an HVAC system consisting of an electric refrigerant compressor, condenser and fan, an expansion valve, an evaporator, and a blower. The refrigerant compressor has a maximum power output of $4350 \mathrm{~W}$. The refrigerant flow ranges between 0.02 and $0.06 \mathrm{~kg} / \mathrm{s}$ with a total of $0.75 \mathrm{~kg}$ in the entire circuit. The cabin blower is limited to a maximum air mass flow of $12 \mathrm{~kg} / \mathrm{min}$ and a maximum electrical power of $162 \mathrm{~W}$. For cabin heating, an electrical Positive Temperature Coefficient (PTC) heater was used. The maximum heating power is limited to $7000 \mathrm{~W}$ with an efficiency of $95 \%$. For the parametrization of the model, we refer to values from test benches and other literature. The software includes the thermal properties of more than 25 fluids. An interface with common software tools, such as Matlab and Excel, allows external control of KULI and automation of the simulation. Furthermore, the main advantage of KULI is the low computing time.

The simulation parameters can be assigned based on a user interface. They were categorized into three groups (Table 2). Moreover, the driving velocity, initial temperature and humidity inside the cabin, the number of passengers, and the transmittivity of the different windows can be entered as simulation parameters.

Table 2. Input parameter of the HVAC and cabin model.

\begin{tabular}{ccc}
\hline Ambient Conditions & Vehicle Concept & HVAC-System \\
\hline Ambient temperature in ${ }^{\circ} \mathrm{C}$ & Cabin surface area in $\mathrm{m}^{2}$ & Set temperature in ${ }^{\circ} \mathrm{C}$ \\
Ambient humidity in $\%$ & Cabin volume in $\mathrm{m}^{3}$ & Blower mass flow $\mathrm{kg} / \mathrm{min}$ \\
Sun position (two angles) in & Windshield angle in & Recirculation ratio in $\%$ \\
Sun intensity in $\mathrm{W} / \mathrm{m}^{2}$ & Side window angle in & \\
Initial cabin temperature in ${ }^{\circ} \mathrm{C}$ & Rear window angle in & \\
Initial cabin humidity in $\%$ & Windshield area in $\mathrm{m}^{2}$ & \\
& Side windows area in $\mathrm{m}^{2}$ & \\
& Rear window area in $\mathrm{m}^{2}$ & \\
\hline
\end{tabular}


Control of the HVAC system is performed by KULI. It controls the refrigerant compressor, the condenser fan, and the PTC heater depending on the ambient conditions, the heat exchange of the cabin, the air mass flow, and the desired set temperature. The energy consumption of the HVAC system, depending on the ambient conditions, the geographic location, and the size and shape of the vehicle cabin can be calculated using the presented KULI model.

\subsection{Modeling of Autonomous Vehicle Concepts}

A tool is needed to calculate the complete vehicle in order to investigate the impact of HVAC consumption on the vehicle concept. We, therefore, use the current version of the autonomous vehicle development tool $(\mathrm{AuVeCoDe})$, which will be provided as open source MATLAB simulation within the dissertation of the first author next year. The first concept of this research was published in [15] and it has now been extended with several already published and validated models:

- Calculation of tires and wheelhouses [38];

- Weight regressions of complete vehicles [39];

- Longitudinal dynamic simulation [40];

- Package calculation of autonomous vehicles [41];

- Calculation of gearboxes for electric powertrains [42];

The longitudinal dynamic simulation and weight regressions already help to roughly recreate the results of this paper together with the following HVAC consumption regressions.

The process (Figure 3) starts with user inputs, e.g., the required interior layout and space and desired range and acceleration. The package is calculated after conducting a first longitudinal dynamic simulation to size the battery, gearbox, and electric machine. The battery design fills the available space with cells and completes the information to estimate the mass of all components. The calculation of auxiliary consumers is optional and can be selected by giving information about the weather scenario and sensor setup. This step integrates the regressions of the HVAC model presented in this paper (Orange, Figure 3). Since the vehicle mass and auxiliary power consumption are an input for the longitudinal dynamic simulation, another iteration must be started with re-calculation of the vehicle. When data such as motor and battery size or vehicle weight converge, the vehicle design is finished, and the resulting vehicle data are given back to the user.

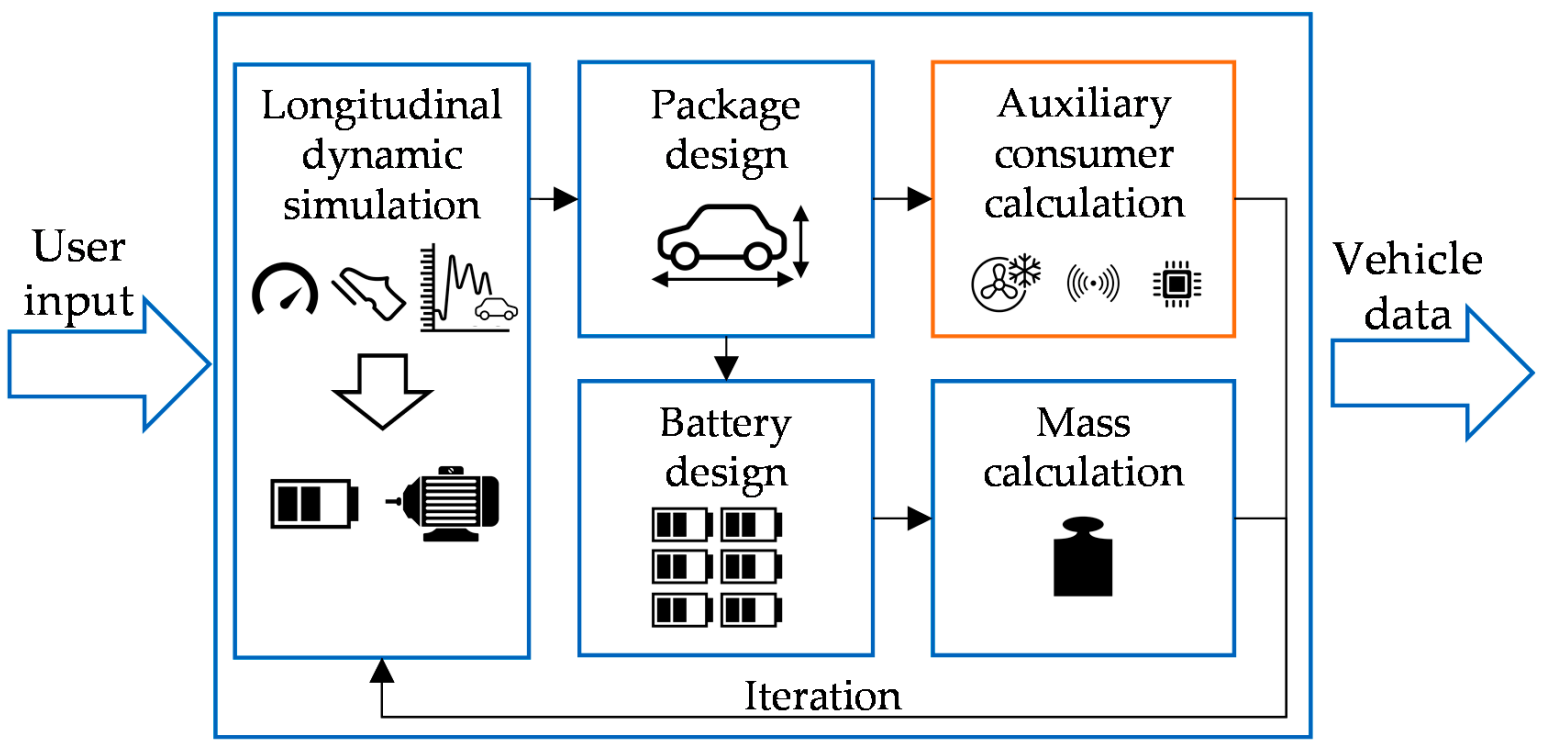

Figure 3. Process and sub-steps of Autonomous Vehicle Concept Development Tool (Orange: Sub-step in which HVAC model is integrated). 
A tool validation with BEVs will be shown in future publications after finalizing all sub-models. Since AVs are not yet available as series production cars, conventional BEVs are used to validate the tool. As an example, we show the current deviation (Table 3) when calculating the Volkswagen (VW) ID.3 and the corresponding plot of the calculated package (Figure 4).

Table 3. Current validation status by example of VW ID.3.

\begin{tabular}{cccc}
\hline Parameter & Manufacturer & Simulation & Deviation \\
\hline Acceleration time 0-100 km/h & $7.3 \mathrm{~s}$ & $7.3 \mathrm{~s}$ & $\sim 0 \%$ \\
Maximum speed & $160 \mathrm{~km} / \mathrm{h}$ & $160 \mathrm{~km} / \mathrm{h}$ & $\sim 0 \%$ \\
Driving range & $426 \mathrm{~km}$ & $430 \mathrm{~km}$ & $+0.9 \%$ \\
Battery capacity (usable) & $58 \mathrm{kWh}$ & $60.3 \mathrm{kWh}$ & $+3.9 \%$ \\
Consumption & $13.6 \mathrm{kWh} / 100 \mathrm{~km}$ & $14.0 \mathrm{kWh} / 100 \mathrm{~km}$ & $+2.9 \%$ \\
Machine max. power & $150 \mathrm{~kW}$ & $160 \mathrm{~kW}$ & $+6.5 \%$ \\
Vehicle empty weight & $1805 \mathrm{~kg}$ & $1843 \mathrm{~kg}$ & $+2.1 \%$ \\
\hline
\end{tabular}

${ }^{1}$ Calculated with range and usable battery capacity, since the consumption provided by the manufacturer includes charging losses.
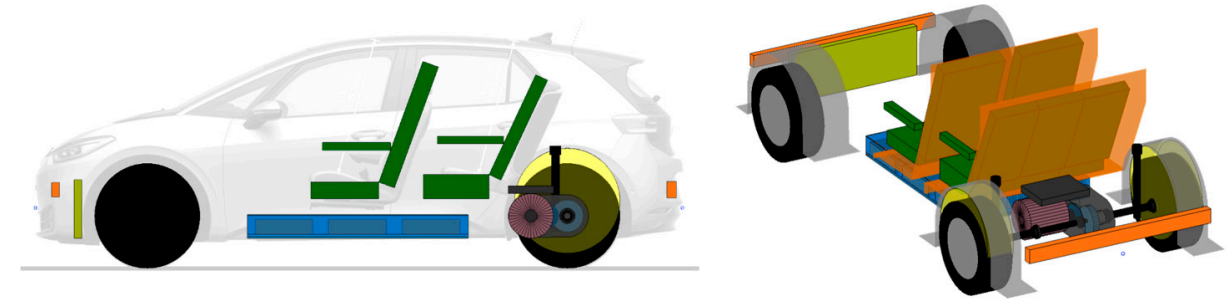

Figure 4. Current VW ID.3 validation status of the package plot of the AuVeCoDe Tool.

The package already exhibits a good fit with the real vehicle, although partial models, such as the body-in-white, are still in progress. The simulation results only show minor deviations, except for the electric machine. This is because we used a Model 3 PMSM efficiency diagram $[43,44]$ for the calculation since we do not yet have an efficiency diagram of a VW ID. 3 available. This diagram has a different ratio of maximum speed to base speed than the actual machine and thus leads to a different ratio of torque to power. However, it provides high accuracy in the consumption simulation due to a similar efficiency distribution.

\section{Validation of HVAC Model}

For an understanding of the behavior of both the cabin and complete HVAC model, we validated them separately. First, the validation of the cabin model is presented, particularly in its behavior of heating due to solar radiation on a BMW i3 and a Volkswagen eGolf. Second, we present the validation of the complete system including the cabin and components for heating and cooling, using our own measurements from a Volkswagen ID3, Tesla Model 3, and BMW i3.

\subsection{Cabin Model}

The cabin model is validated using heating curves due to solar radiation. The cabin model includes the heat exchange between the interior and environment and the influence of solar radiation entering through the windows. To measure the heating curves of the real cars, a specific orientation of the vehicle towards the sun and a specific day time was defined. This configuration was later also set in the simulation model. The change in the air temperature inside the real vehicle was measured by placing temperature loggers at the head and foot area in the car. These temperatures are used to calculate an average interior temperature. The first vehicle, a VW eGolf, results in a maximum deviation of $1.34{ }^{\circ} \mathrm{C}$ $(5.53 \%)$ and a mean absolute percentage error of $2.14 \%$ (Figure 5). 


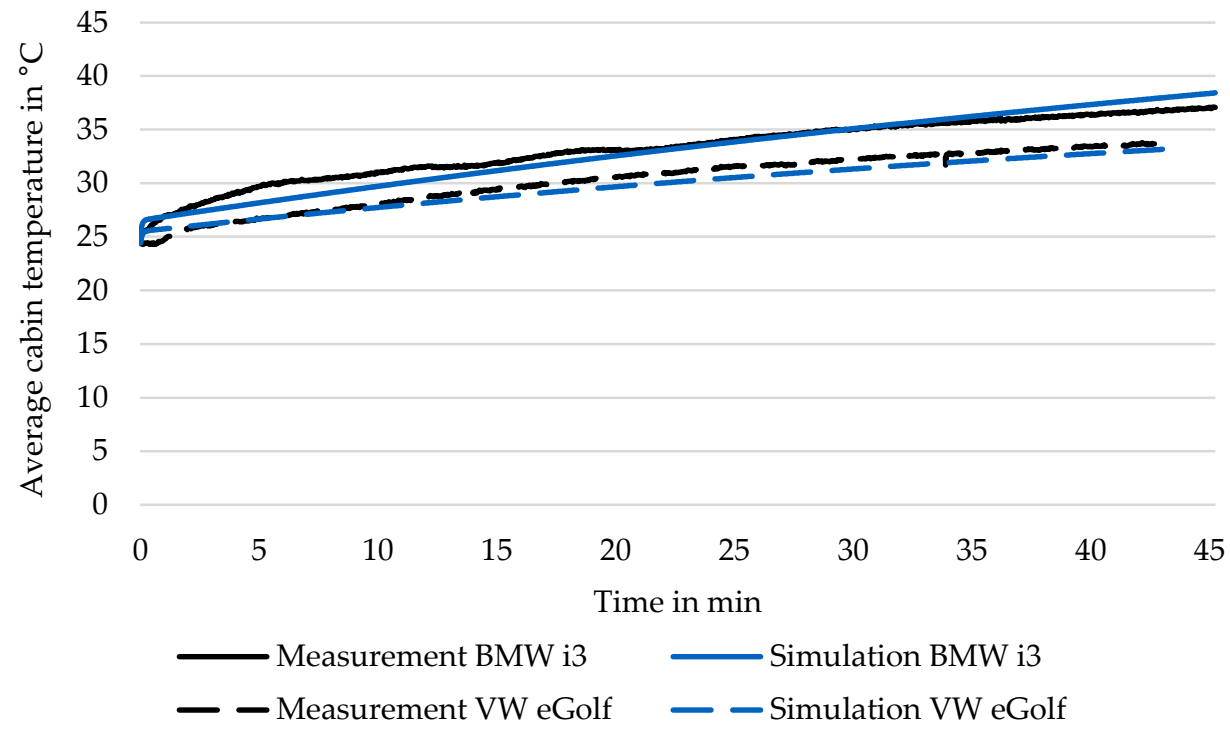

Figure 5. Comparison between heating curve of a Volkswagen eGolf/BMW i3 and simulation.

The second vehicle, a BMW i3, could also be replicated by the model, with a maximum temperature deviation of $1.69{ }^{\circ} \mathrm{C}(5.62 \%)$ and a mean absolute percentage error of $2.22 \%$ (Figure 5). The validation indicates that the cabin model is suitable for predicting the average air temperature within the passenger compartment. The deviations were mainly caused by unknown material characteristics and simplifications in the simulation model like a single volume cabin, constant solar radiation, and sun angle.

\subsection{Complete Model}

In the next step, the HVAC model was validated, focusing on its energy consumption for heating and cooling the passenger compartment. In this context, we look at the power of the PTC-heater and the refrigerant compressor. Due to the lack of data, the power of the fans was neglected. This assumption can also be made because the PTC-heater and refrigerant compressor are responsible for the majority of the total energy consumption of the system. For the validation, the BMW i3, the Tesla Model 3, and the Volkswagen ID.3 were used for having a holistic validation with different cars and different ambient conditions. While the BMW i3 and Model 3 could be used for the validation of the heating model, only the VW ID.3 could be used for the cooling model. This was due to the limited availability of data from those vehicles. A data logger plugged into the on-board diagnostic connector collected information about the HVAC consumption and temperatures inside and outside the car and the HVAC settings (e.g., the set temperature).

For cooling the VW ID.3, a different set temperature was used, having different measured sun intensities due to a changing sun angle. The set temperatures vary between $18{ }^{\circ} \mathrm{C}$ and $21{ }^{\circ} \mathrm{C}$. The former is adjusted to a sun intensity of $850 \mathrm{~W} / \mathrm{m}^{2}$, the latter to $650 \mathrm{~W} / \mathrm{m}^{2}$. Both values could be collected from a measurement station near the vehicle [45]. Table 4 shows the validation of the approach based on the three cars.

The deviations can be explained with the simple cabin model on the one side, which only provides one average temperature of the cabin. On the other side, parameters of the vehicle, such as the heat transfer coefficient, are not known and have to be estimated. Furthermore, the battery and other components that can thermally interact with the cabin or the coolant cycle were not considered. Nevertheless, the model reproduces the measurement data sufficiently and accurately and is suitable for calculating the energy consumption for heating and cooling the passenger compartment. 
Table 4. Validation of the HVAC model using the energy consumption for heating and cooling of the passenger compartment.

\begin{tabular}{cccccc}
\hline Vehicle & $\begin{array}{c}\text { Ambient } \\
\text { Temperature }\end{array}$ & $\begin{array}{c}\text { Set } \\
\text { Temperature }\end{array}$ & Simulation & Measurement & Derivation \\
\hline \multirow{2}{*}{ BMW i3 } & $6.06^{\circ} \mathrm{C}$ & $24^{\circ} \mathrm{C}$ & $1557 \mathrm{~W}$ & $1393 \mathrm{~W}$ & $11.77 \%$ \\
$($ Heating) & $3.54{ }^{\circ} \mathrm{C}$ & $23^{\circ} \mathrm{C}$ & $1447 \mathrm{~W}$ & $1318 \mathrm{~W}$ & $9.79 \%$ \\
& $-2.80^{\circ} \mathrm{C}$ & $24^{\circ} \mathrm{C}$ & $2454 \mathrm{~W}$ & $2277 \mathrm{~W}$ & $7.77 \%$ \\
\hline Tesla Model 3 & $4.37^{\circ} \mathrm{C}$ & $20^{\circ} \mathrm{C}$ & $2917 \mathrm{~W}$ & $2963 \mathrm{~W}$ & $-1.55 \%$ \\
(Heating) & $11.9^{\circ} \mathrm{C}$ & $20^{\circ} \mathrm{C}$ & $1454 \mathrm{~W}$ & $1408 \mathrm{~W}$ & $3.27 \%$ \\
\hline VW ID.3 & $24^{\circ} \mathrm{C}$ & $18^{\circ} \mathrm{C}$ & $1439 \mathrm{~W}$ & $1553 \mathrm{~W}$ & $-7.34 \%$ \\
(Cooling) & $25^{\circ} \mathrm{C}$ & $21^{\circ} \mathrm{C}$ & $566 \mathrm{~W}$ & $604 \mathrm{~W}$ & $-6.29 \%$ \\
\hline
\end{tabular}

\section{Regressions}

Since thousands of calculations have to be performed during the concept development optimization, the computing time of the simulation has to be minimized. For this reason, we decided to derive a meta model built with regressions. They result in low computing time and can be integrated into every other model to estimate the energy consumption due to HVAC.

For the scope of this research, the weather parameters are reduced to three different scenarios (Table 5). Because we want to estimate the greatest possible change in the vehicle concept, we decide to choose worst case scenarios for winter and summer. To cover all possible weather scenarios, the variety of inputs would have to be extended and more complex metamodels would be required. If computing time does not play a major role, the HVAC simulation model can also be directly integrated into the concept development tool, which would lead to higher accuracy and the possibility to select weather configurations different from the three mentioned in Table 5.

Table 5. Climate scenarios.

\begin{tabular}{cccc}
\hline Parameter & Winter & Spring/Fall & Summer \\
\hline Operation mode & Heating & Heating & Cooling \\
Angle of sun & - & $45^{\circ}$ & $60^{\circ}$ \\
Solar radiation & - & $450 \mathrm{~W} / \mathrm{m}^{2}$ & $850 \mathrm{~W} / \mathrm{m}^{2}$ \\
Ambient temperature & $-8-5{ }^{\circ} \mathrm{C}$ & $10^{\circ} \mathrm{C}$ & $25-32^{\circ} \mathrm{C}$ \\
\hline
\end{tabular}

For the winter scenario, we do not consider heating of the cabin due to solar radiation, which corresponds to a very cloudy day with low sun. For the summer scenario, we consider a high sun position in Munich, which is around $60^{\circ}$, and solar radiation of $850 \mathrm{~W} / \mathrm{m}^{2}$. For the moderate scenario, the sun position is reduced to $45^{\circ}$ and the solar radiation to $450 \mathrm{~W} / \mathrm{m}^{2}$.

Either the model for heating or the model for cooling can be used during the calculation of the regression. A mixed scenario, where the need for heating or cooling depends on the vehicle and window sizes, is therefore not possible. Consequently, the ambient temperature of $10^{\circ} \mathrm{C}$ for the spring/fall scenario was selected to ensure the operation mode of heating for every vehicle and window size.

As an initial step for deriving the regression model, the most influential parameters were determined that are relevant for HVAC consumption. For this scope, we conducted a sensitivity analysis for every above-mentioned scenario to evaluate the influence of every parameter on the energy consumption in the model. The sensitivity analysis shows that different parameters were relevant for the different scenarios. Table 6 shows the most important parameters. 
Table 6. Table of relevant input parameters for regressions.

\begin{tabular}{ccc}
\hline Winter & Spring/Fall & Summer \\
\hline Ambient temperature $\mathrm{T}_{\mathrm{Amb}}$ & Ambient temperature $\mathrm{T}_{\mathrm{Amb}}$ & Ambient temperature $\mathrm{T}_{\mathrm{Amb}}$ \\
Blower mass flow $\dot{\mathrm{m}}_{\text {Blower }}$ & Vehicle type & Vehicle type \\
Cabin surface area $\mathrm{A}_{\text {Cabin }}{ }$ & Windshield angle $\alpha$ & Side window angle $\beta$ \\
Percentage circulated air $\mathrm{p}_{\text {circair }}$ & Side window angle $\beta$ & Rear window angle $\gamma$ \\
& Rear window angle $\gamma$ & Windshield area $\mathrm{A}_{\text {Front }}$ \\
& Windshield area $\mathrm{A}_{\text {Front }}$ & Side window area $\mathrm{A}_{\text {Side }}$ \\
& Side window area $\mathrm{A}_{\text {Side }}$ & Rear window area $\mathrm{A}_{\text {Rear }}$ \\
& Rear window area $\mathrm{A}_{\text {Rear }}$ & Cabin surface area $\mathrm{A}_{\text {Cabin }}$ \\
\hline
\end{tabular}

While only one regression shows good results for the heating scenario, several have to be calculated for the moderate and cooling scenarios to get satisfactory results. This is because, on the one hand, the value range for window angles and surface areas is divided into conventional vehicles and one-box design vehicles. On the other hand, using only one regression for the summer scenario leads to high deviations of the regression compared to the simulation data. A possible reason could be the variable efficiency of the compressor, the heat exchange between the refrigerant and the air and the HVAC control. Consequently, a separate regression is created for every ambient temperature in the summer scenario, which improves the results.

The value range for the conventional vehicles is defined by measuring several vehicles (Table 7) selected from different body types (Hatchback, Sedan, SUV, Mini-Van) and classes. The parameter set is selected so that most of the vehicles are covered. We also include three examples for autonomous one-box design (VW Sedric, Cruise Origin and autoTAXI) to cover non-conventional shapes. The values of the side window area refer only to the one side of the vehicle (left or right) due to symmetry.

Table 7. Table of relevant input parameters for regressions.

\begin{tabular}{|c|c|c|c|}
\hline Vehicle & $\begin{array}{c}\text { Front Window } \\
{\text { A Front in } \mathrm{m}^{2} / \alpha \text { in }}^{\circ}\end{array}$ & $\begin{array}{c}\text { Side Window } \\
{\text { A Side in } \mathrm{m}^{2} / \beta \text { in }}^{\circ}\end{array}$ & $\begin{array}{c}\text { Rear Window } \\
A_{\text {Rear in } \mathrm{m}^{2} / \gamma \text { in }}\end{array}$ \\
\hline Smart ForTwo ${ }^{1}$ & $1.0 / 52$ & $0.35 / 70$ & $0.46 / 18$ \\
\hline VW Polo $^{1}$ & $1.16 / 29$ & $0.5 / 65$ & $0.5 / 40$ \\
\hline BMW i3 ${ }^{1}$ & $1.4 / 31$ & $0.78 / 67$ & $0.48 / 44$ \\
\hline VW ID. $3^{1}$ & $1.36 / 27$ & $0.67 / 65$ & $0.5 / 41$ \\
\hline VW eGolf $^{1}$ & $1.2 / 29$ & $0.6 / 65$ & $0.5 / 49$ \\
\hline BMW X5 ${ }^{1}$ & $1.3 / 33$ & $0.8 / 67$ & $0.6 / 43$ \\
\hline BMW $7 e{ }^{1}$ & $1.2 / 31$ & $0.57 / 65$ & $1.1 / 24$ \\
\hline VW Touran ${ }^{1}$ & $1.3 / 30$ & $0.9 / 74$ & $0.58 / 59$ \\
\hline VW Sedric $^{2}$ & $0.3 / 62$ & $1.5 / 83$ & $0.5 / 69$ \\
\hline Cruise Origin $^{2}$ & $0.7 / 90$ & $1.3 / 87$ & $0.7 / 90$ \\
\hline autoTAXI $^{1}$ & $1.8 / 72$ & $1.16 / 86$ & $1.6 / 72$ \\
\hline
\end{tabular}

${ }^{1}$ Own measurement, ${ }^{2}$ Estimation based on pictures.

Using the simulation model in KULI, we create a data set to adapt the model and a data set to prove the accuracy of the regression. As mentioned, we differ between conventional (e.g., SUV, Sedan) and one-box design vehicles in the summer and spring/fall scenario. For the winter scenario, this differentiation is not considered since solar radiation is neglected. Table 8 shows the variation within the relevant input parameters for the regression for the 
two vehicle groups. In both cases, the cabin surface area $\mathrm{A}_{\text {Cabin }}$ was varied between 5, 7.5, and $10 \mathrm{~m}^{2}$.

Table 8. Differentiation between conventional and One-Box design vehicles based on their exterior dimensions.

\begin{tabular}{ccc}
\hline Parameter & Conventional & One-Box-Design \\
\hline Windshield area $A_{\text {Front }}$ & $1.1-1.5$ & $0.6-1.8$ \\
Rear window area $A_{\text {Rear }}$ & $0.4-1.0$ & $0.6-1.8$ \\
Side window area A $A_{\text {Side }}$ & $0.5-1.1$ & $1.1-1.7$ \\
Windshield angle $\alpha$ & $25-40$ & $75-90$ \\
Side window angle $\beta$ & $65-85$ & $75-85$ \\
Rear window angle $\gamma$ & $20-60$ & $75-90$ \\
\hline
\end{tabular}

To find the best compromise between under- and over-fitting, we fit equations with linear and quadratic correlations. For every solution, the deviation for the data points used is evaluated. Furthermore, we conduct inter- and extrapolation with additional data points, which were not used for the calculation of the regression. The results show that the combination of a simple linear regression led to the best results (Equation (1)). Input is the parameters $x$ (Table 6), output is the energy consumption $E$, and the coefficients $p$ have to be determined using the simulation data.

$$
\begin{gathered}
E_{\operatorname{Reg}}\left(x_{1}, \ldots, x_{n}\right)= \\
p_{1} x_{1}+\ldots+p_{n} x_{n}+x_{1}\left(p_{n+1} x_{2}+\ldots+p_{n+(n-1)} x_{n}\right)+\ldots+x_{n-1}\left(p_{i=n(n+1) / 2} x_{n}\right)+p_{i+1}
\end{gathered}
$$

The mean and maximum absolute and relative error show only small deviation (Table 9) for the data points used for the regression, as well as additional data points tested for inter- and extrapolation. A range of error is given for the spring/fall and summer scenarios since several regressions are used to achieve higher accuracy. The maximum error, especially in the summer, is caused by complex relationships, such as unfavorable operating points of the compressor, that cannot be represented with linear regression. Nevertheless, polynomial regressions showed especially worse results for inter- and extrapolation due to overfitting, which is why we decided to use linear regressions.

Table 9. Deviation of the regressions to the simulated data points.

\begin{tabular}{cccc}
\hline Type of Error & Winter & Spring/Fall & Summer \\
\hline Mean absolute error (MAE) & $20.4 \mathrm{~W}$ & $0.91-3.3 \mathrm{~W}$ & $8.4-73 \mathrm{~W}$ \\
Mean relative error (MRE) & $0.7 \%$ & $0.06-0.27 \%$ & $1.3-3.1 \%$ \\
Maximal error & $114 \mathrm{~W} / 10.4 \%$ & $11.2 \mathrm{~W} / 2.5 \%$ & $631 \mathrm{~W} / 18.5 \%$ \\
(absolute/relative) & $0.9 \%$ & $0.04-0.24 \%$ & $1.4-2.8 \%$ \\
MRE interpolation & $3.8 \%$ & $0.06-0.37 \%$ & $1.2-2.8 \%$ \\
MRE extrapolation & & & \\
\hline
\end{tabular}

We did not include parameters in the appendix due to the high quantity of numbers, which therefore needed space. Instead, the regressions can be downloaded from Github [46], including an already usable MATLAB function for the calculation.

\section{Results}

In this section, we present the results obtained with the AuVeCoDe Tool and show the influence on the vehicle when the HVAC consumption is already considered in the early development phase. For this scope, the HVAC meta-model was included in the $\mathrm{AuVeCoDe}$ tool, and three autonomous and electric vehicles are investigated with variable ambient temperatures. The small-size vehicle, mid-size vehicle, and vehicle with onebox design are shown in Table 10. We use two different driving cycles to differentiate between the conventional development (WLTP cycle) and development for urban areas 
(ARTEMIS Urban cycle). Furthermore, we use the summer and winter scenarios as worstcase scenarios and do not consider additional consumption by HVAC in a reference scenario in order to have a basis for comparison. We take the mid-size vehicle as our reference vehicle and impose with a range similar to the VW ID.3 in the WLTP cycle, which is $420 \mathrm{~km}$. In the ARTEMIS Urban cycle, the average speed is $17.65 \mathrm{~km} / \mathrm{h}$, whereas the WLTP cycle is $46.50 \mathrm{~km} / \mathrm{h}$. We assume the operation time is the same for every vehicle, which is about $9 \mathrm{~h}$. Considering the lower average speed, this means only about $160 \mathrm{~km}$ of range in the ARTEMIS Urban cycle to achieve equal operation time. Although the HVAC is normally switched off during these cycles, we consider HVAC consumption to show its influence.

Table 10. Investigated autonomous and electric vehicles: small vehicle, mid-size vehicle, one-box design vehicle.

\begin{tabular}{|c|c|c|c|}
\hline Input Parameter & Small Vehicle (e.g., Smart Fortwo ${ }^{1}$ ) & Mid-Size Vehicle (e.g., VW ID3 ${ }^{1}$ ) & One-Box Vehicle (e.g., Autotaxi) \\
\hline \multicolumn{4}{|l|}{ Plot of package } \\
\hline Driving range & WLTP: n.a.ARTEMIS U.: 160 km & WTLP: 420 kmARTEMIS U.: 160 km & WTLP: 420 kmARTEMIS U.: 160 km \\
\hline Maximum speed & $130 \mathrm{~km} / \mathrm{h}$ & $160 \mathrm{~km} / \mathrm{h}$ & $130 \mathrm{~km} / \mathrm{h}$ \\
\hline $\begin{array}{l}\text { Acceleration } \\
0-100 \mathrm{~km} / \mathrm{h}\end{array}$ & $11 \mathrm{~s}$ & $7.6 \mathrm{~s}$ & $10 \mathrm{~s}$ \\
\hline Seating layout & Single rowTwo seats & ConventionalFive seats & Vis-à-visFour seats \\
\hline
\end{tabular}

${ }^{1}$ Assumption that this vehicle would be available as an autonomous vehicle.

Depending on the given scenarios, all three vehicles are calculated, and the resulting battery capacity is plotted (Figures 6 and 7). For all scenarios, a basic auxiliary consumption is considered in addition to the HVAC consumption. As mentioned in Section 1, the consumption due to sensors and computers has high uncertainty. We, therefore, calculated with an optimistically low consumption of $600 \mathrm{~W}$ [47] (p. 4). We assume this consumption to be the same for every vehicle size to get better comparability and because the type and number of sensors and computers required are probably dependent on the automation level and not the vehicle size.

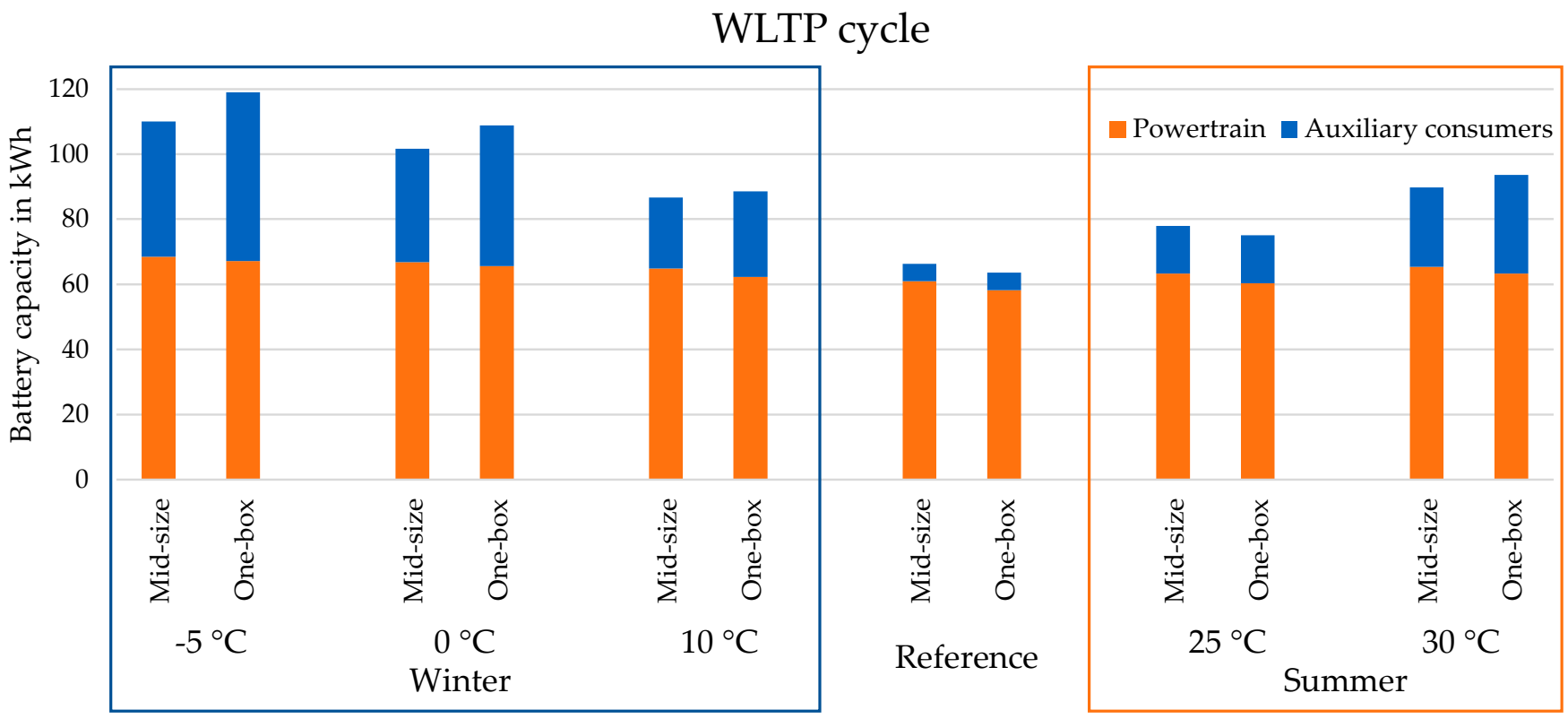

Figure 6. Change of battery size depending on weather scenario using the WLTP cycle for mid-sized vehicle and one-box vehicle. 


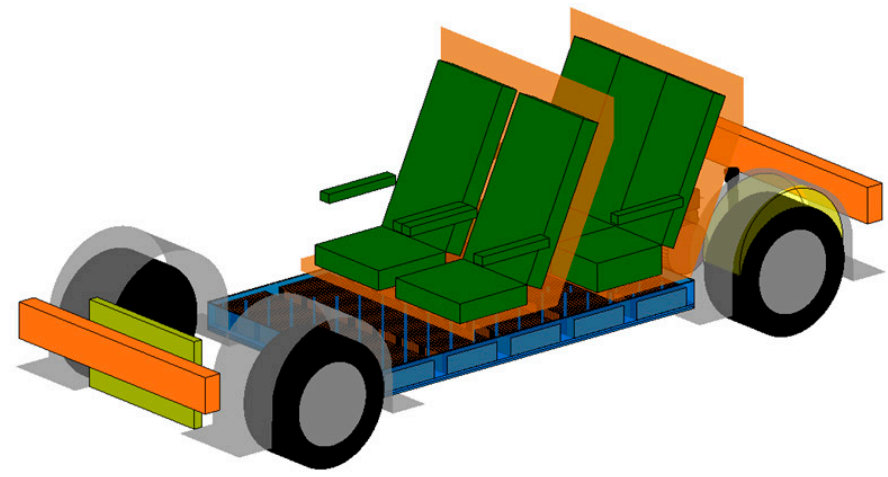

Mid-size

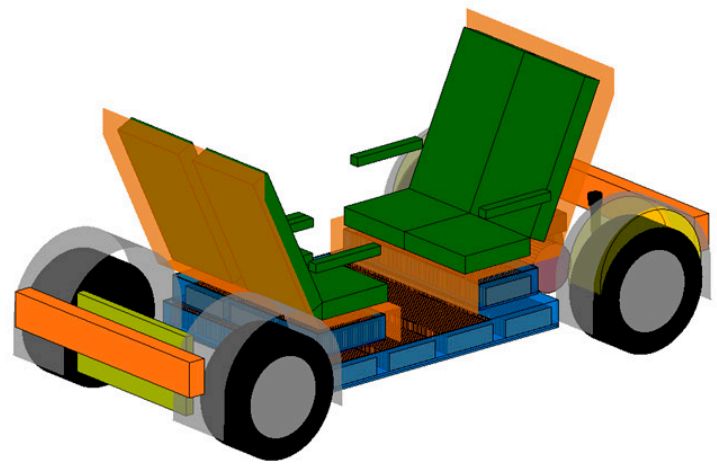

One-box

Figure 7. Usage of available battery space for vehicles sized based on the WTLP cycle with ambient temperature of $-5{ }^{\circ} \mathrm{C}$ and a desired range of $420 \mathrm{~km}$.

For the WLTP cycle (Figure 6), we only considered the mid-size and one-box vehicle, because a range of $420 \mathrm{~km}$ was not achievable with the small-size vehicle due to missing package space for the battery. The winter scenario causes higher consumption than summer, which agrees well with the literature. The main reason for this is a lower conversion efficiency by the PTC heater $(<1)$ in comparison to the climate compressor (Coefficient of Performance $(\mathrm{COP})>1$ ). In both cases, the one-box vehicle is more sensitive to changing weather conditions. The maximal increase of battery for this vehicle is $87 \%$ in the winter scenario, mainly due to a higher cabin surface, which leads to a higher loss of heating energy to the outside. The one-box vehicle also has a higher energy demand for the summer scenario because of the larger windshield and side windows. They cause higher solar radiation into the cabin and, as a consequence, a maximal battery increase of $47 \%$.

The change in powertrain consumption due to a larger battery, and thus a high vehicle mass, is only minor. On the one hand, the cause lies in the fact that a dominant percentage of aerodynamic drag determines the energy demand in the WLTP, and neither frontal surface nor the drag coefficient are affected by the battery sizing. On the other hand, BEVs are not as sensitive to mass as ICEVs because they can recuperate energy during braking.

The vehicles designed for $-5^{\circ} \mathrm{C}$ almost require the entire available battery space due to the higher HVAC consumption (Figure 7). For temperatures below $-5^{\circ} \mathrm{C}$, the simulation leads to unfeasible vehicles since the required battery capacity no longer fits in the available installation space. For these temperatures, the target range has to be reduced or the vehicle needs to be redesigned to provide more battery space.

Vehicles designed for an urban application and identical operation time can be equipped with a much lower battery compared to vehicles designed with the WLTP cycle (Figure 8). Especially, a lower average speed leads to reduced energy demand from the powertrain. However, when using HVAC, the required battery capacity increases significantly more. The reason for this is the time-dependent energy consumption of the HVAC system. The slower the vehicle is driving, the more sensitive it is to auxiliary power consumers since the percentage of needed auxiliary energy per distance is increasing. This was also stated by Grube [9].

Again, the one-box vehicle has the highest consumption caused by higher cabin and glass surfaces. The increase is significantly higher than for the WLTP. For heating, a battery enlargement of $250 \%$ is required, and for cooling, $134 \%$ is required, or in other words, more than a tripling of the battery size. In comparison to the WLTP, the auxiliary consumers already cause more than half of the total energy demand for $10^{\circ} \mathrm{C}$ ambient temperature. 


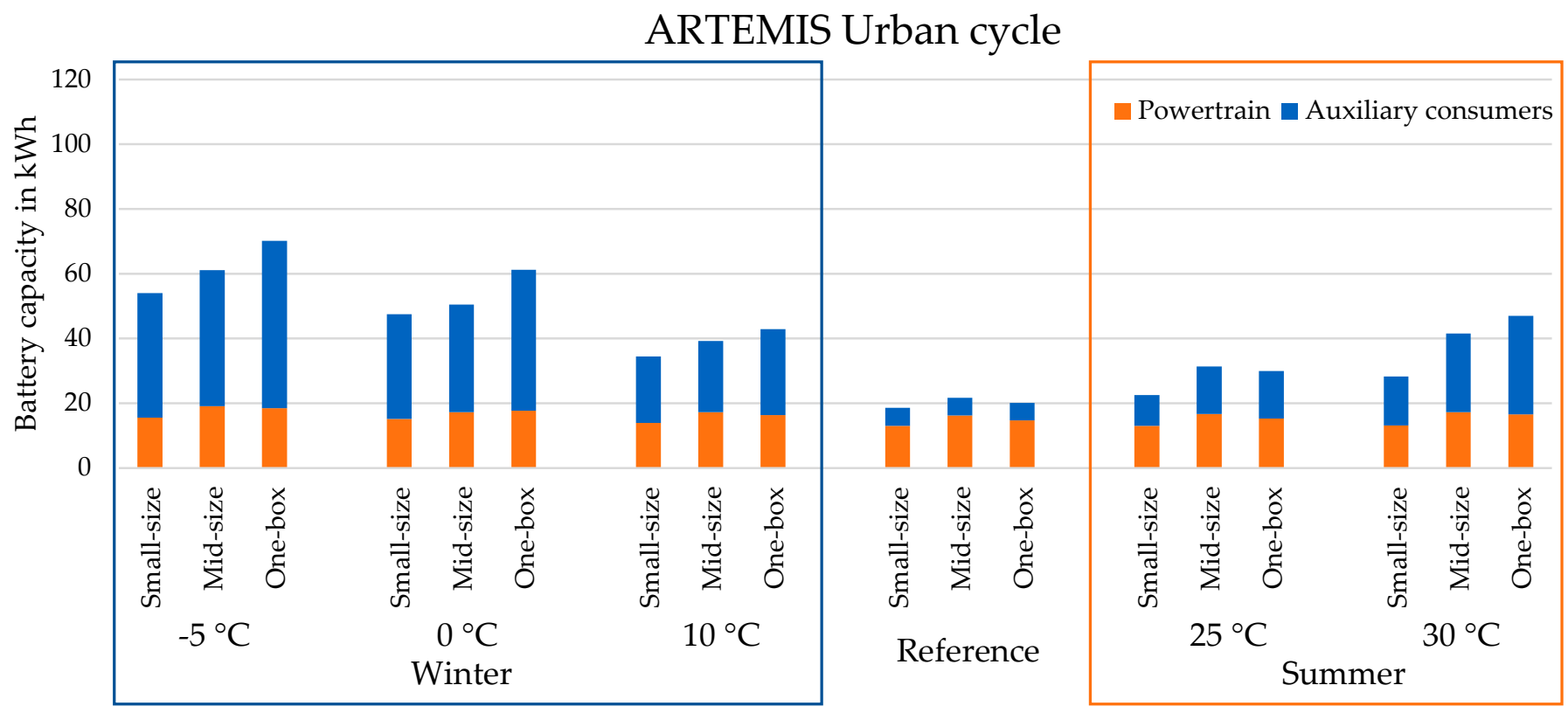

Figure 8. Change of battery size depending on weather scenario using the ARTEMIS Urban cycle for a small-sized vehicle, a mid-sized vehicle, and a one-box vehicle.

\section{Conclusions}

The results from Section 6 show that for urban or in general low-speed applications, the auxiliary consumers can demand more than half of the total energy. Consequently, improvements of auxiliary consumers are as important as, or even more important than, the powertrain to reduce battery size and thus costs. Especially heating with PTC heaters still has efficiency disadvantages, which is why the use of heat pumps should be promoted and expanded.

Another result is the recommendation that auxiliary consumers should be considered as a requirement for the development of autonomous vehicles since they have a strong influence on the battery size. Depending on cabin surface area, window area and angles, and weather scenario, significantly different sizes of batteries are required to achieve the same driving range. For both winter and summer scenarios, the cabin surface area should be minimized to reduce the loss of heating or cooling energy to the ambient surroundings, which thus decreases energy demand. In the summer scenario, higher window areas lead to higher energy demand due to solar radiation heating up the cabin, in addition to heat transfer through the cabin walls.

To be capable of achieving desired ranges, especially in urban areas with high solar radiation, the window areas should be reduced to a minimum, where a compromise between economy and ergonomics is achieved. If autonomous vehicles are designed without a driver space, the windows can be more tinted since laws on visibility to the outside no longer have to be fulfilled. Better insulation also helps to reduce energy losses, especially during cold ambient temperatures. The reduced consumption and the resulting smaller battery size could amortize their costs.

\section{Discussion and Outlook}

Several simplifications have to be made during the development of the HVAC model. Due to computing time, the vehicle cabin is modelled with the single-volume method. This requires assuming that the average temperature in the vehicle cabin has no differentiation between the temperatures in the first and second row and the neglect of temperature stratification. In reality, there is a division of air flows for the foot and head areas caused by different temperatures of the incoming air flows. Modeling the vehicle cabin with the single-volume method also complicates the validation. Due to a lack of data, assumptions 
have been made for the transmittivity of the different windows. Furthermore, two different refrigerants are used in the cooling validation. The simulation model works with the refrigerant R1234yf, and the VW ID.3 uses R744. Information was neither available on the interaction between the HVAC system and the cooling of the battery storage unit nor the size and layout of the condenser and evaporator.

The regression models of Section 5 deviate with a discrepancy from the simulation model in KULI. Depending on the cabin geometry and the environmental conditions, deviations of several hundred watts can occur in individual cases. These deviations show the trade-off between the degree of modeling and the computing time. However, the substitute models are suitable for interpolation and extrapolation as shown.

The results show three vehicles as examples with specific weather configurations. In reality, the weather conditions and sun position are constantly changing and thus lead to continuous slight changes in HVAC consumption and driving ranges. Nevertheless, the calculation of best and worst cases gives the range of needed battery capacities to developers and researchers and helps them make fleet planning decisions.

At this time, HVAC and other auxiliary power consumers are not considered when estimating the consumption and range of a vehicle. This could change in the future since the results show that HVAC is, especially with lower speeds, as important as the powertrain in terms of energy demand. The European Union also plans to consider eco-innovations, such as a more efficient HVAC system, in addition to the powertrain from 2025 [48]. So far, only measures to the powertrain, for example by coasting functions or more efficient alternators, have been considered [48] (p. 5).

Author Contributions: As the first author, A.K. defined the approach for modeling autonomous vehicle concepts and their auxiliary consumers and identified the need for a new HVAC model. S.M. reviewed existing HVAC models and built up the HVAC model with the support of S.T. and A.K. A.K. and S.M. collected and measured the needed data for validation and derived the regressions. L.N. supported with the definition of the concept and proofread the paper. M.L. made an essential contribution to the conception of the research project. He revised the paper critically for important intellectual content. M.L. gave final approval of the version to be published and agrees to all aspects of the work. As a guarantor, he accepts responsibility for the overall integrity of the paper. All authors have read and agreed to the published version of the manuscript.

Funding: The research of A.K. was accomplished within the project "UNICARagil” (FKZ 16EMO0288) We acknowledge the financial support for the project from the Federal Ministry of Education and Research of Germany (BMBF). The research of L.N. was funded by the AUDI AG and the Technical University of Munich.

Institutional Review Board Statement: Not applicable.

Informed Consent Statement: Not applicable.

Data Availability Statement: Not applicable.

Conflicts of Interest: The authors declare no conflict of interest and had no role in the design of the study, in the collection, analyses, interpretation of data, in the writing of the manuscript, or in the decision to publish the results.

\section{References}

1. Nicoletti, L.; Brönner, M.; Danquah, B.; Koch, A.; König, A.; Krapf, S.; Pathak, A.; Schockenhoff, F.; Sethuraman, G.; Wolff, S.; et al Review of Trends and Potentials in the Vehicle Concept Development Process. In Proceedings of the 2020 Fifteenth International Conference on Ecological Vehicles and Renewable Energies (EVER), Monte-Carlo, Monaco, 10-12 September 2020; pp. 1-15, ISBN 978-1-7281-5641-5.

2. Stoma, M.; Dudziak, A.; Caban, J.; Droździel, P. The Future of Autonomous Vehicles in the Opinion of Automotive Market Users. Energies 2021, 14, 4777. [CrossRef]

3. Hauff, K.; Pfahl, S.; Degenkolb, R. Taxation of Electric Vehicles in Europe: A Methodology for Comparison. WEVJ World Electr. Veh. J. 2018, 9, 30. [CrossRef]

4. European Environment Agency. Monitoring of $\mathrm{CO}_{2}$ Emissions from New Passenger Cars-Regulation (EU) No $2019 / 631$. Available online: https:/ / www.eea.europa.eu/data-and-maps/data/co2-cars-emission-20 (accessed on 8 October 2021). 
5. König, A.; Nicoletti, L.; Schröder, D.; Wolff, S.; Waclaw, A.; Lienkamp, M. An Overview of Parameter and Cost for Battery Electric Vehicles. WEVJ 2021, 12, 21. [CrossRef]

6. Peters, P.L.; Demuth, R.; Schramm, D. Evaluation of the effects of trends on vehicle concepts based on a forecast of travel demand In 19 Internationales Stuttgarter Symposium; Bargende, M., Reuss, H.-C., Wagner, A., Wiedemann, J., Eds.; Springer Fachmedien Wiesbaden: Wiesbaden, Germany, 2019; pp. 571-587, ISBN 978-3-658-25938-9.

7. Pfriem, M. Analyse der Realnutzung von Elektrofahrzeugen in Kommerziellen Flotten zur Definition Einer Bedarfsgerechten Fahrzeugauslegung. Ph.D. Thesis, KIT Karlsruher Institute for Technology, Karlsruhe, Germany, 2015.

8. Zacharof, N.G.; Fontaras, G. Review of in Use Factors Affecting the Fuel Consumption and $\mathrm{CO}_{2}$ Emissions of Passenger Cars; JRC Science for Policy Report JRC100150; Luxembourg, 2016. Available online: https:/ / op.europa.eu/s/nwEz (accessed on 20 July 2021).

9. Grube, T.; Stolten, D. The Impact of Drive Cycles and Auxiliary Power on Passenger Car Fuel Economy. Energies 2018, 11, 1010. [CrossRef]

10. Al Faruque, M.A.; Vatanparvar, K. Modeling, analysis, and optimization of Electric Vehicle HVAC systems. In Proceedings of the 2016 21st Asia and South Pacific Design Automation Conference (ASP-DAC), Macao, 25-28 January 2016; pp. 423-428, ISBN 978-1-4673-9569-4.

11. Gawron, J.H.; Keoleian, G.A.; de Kleine, R.D.; Wallington, T.J.; Kim, H.C. Life Cycle Assessment of Connected and Automated Vehicles: Sensing and Computing Subsystem and Vehicle Level Effects. Environ. Sci. Technol. 2018, 52, 3249-3256. [CrossRef]

12. Nicoletti, L.; Mayer, S.; Brönner, M.; Schockenhoff, F.; Lienkamp, M. Design Parameters for the Early Development Phase of Battery Electric Vehicles. WEVJ World Electr. Veh. J. 2020, 11, 47. [CrossRef]

13. Matz, S. Nutzerorientierte Fahrzeugkonzeptoptimierung in Einer Multimodalen Verkehrsumgebung. Ph.D. Thesis, Technical University of Munich, Munich, Germany, 2015.

14. Kuchenbuch, K. Methodik zur Identifikation und zum Entwurf Packageoptimierter Elektrofahrzeuge. Ph.D. Thesis, Technical University of Braunschweig, Braunschweig, Germany, 2012.

15. König, A.; Schockenhoff, F.; Koch, A.; Lienkamp, M. Concept Design Optimization of Autonomous and Driverless Vehicles In Proceedings of the 8th International Conference on Power Science and Engineering, Dublin, Ireland, 2-4 December 2019.

16. Schockenhoff, F.; König, A.; Zähringer, M.; Lienkamp, M. User Need-oriented Concept Development of Autonomous Vehicles. Proc. Des. Soc. 2021, 1, 3349-3358. [CrossRef]

17. Wagner, S. Idealisierte energetisch-analytische Abbildungsmethode der Temperaturschichtung bei der passiven Aufheizung in der Fahrzeugkabine. In PKW-Klimatisierung VI: Aktuelle Entwicklungen, Konzepte zur Reduzierung des Mehrverbrauchs, Klimatisierung von Hybridfahrzeugen; [Tagungsband der sechsten Veranstaltung "PKW-Klimatisierung"; Hofhaus, J., Ed.; Expert-Verl.: Renningen, Germany, 2010; pp. 94-110, ISBN 9783816929345.

18. Vatanparvar, K.; Al Faruque, M.A. Battery lifetime-aware automotive climate control for electric vehicles. In Proceedings of the 52nd Annual Design Automation Conference, San Francisco, CA, USA, 7-11 June 2015; ACM: New York, NY, USA; pp. 1-6, ISBN 9781450335201.

19. Broglia, L.; Autefage, G.; Ponchant, M. Impact of passenger thermal comfort and electric devices temperature on range: A system simulation approach. World Electr. Veh. J. 2012, 5, 1082-1089. [CrossRef]

20. Fritz, M. Entwicklungswerkzeuge für die Fahrzeugklimatisierung von Nutzfahrzeugen. Ph.D. Thesis, Karlsruher Institute for Technology, Karlsruhe, Germany, 2015.

21. Fritz, M.; Gauterin, F.; Wessling, J. Computational Time Optimized Simulation Model for Increasing the Efficiency of Automotive Air Conditioning Systems. In SAE Technical Paper Series; SAE International400 Commonwealth Drive: Warrendale, PA, USA, 2014.

22. Ganesan, A.; Jaiswal, R.; Pitchaikani, A. A Study of an Integrated HVAC-Vehicle Model for Automotive Vehicles. SAE Int. J. Passeng. Cars Mech. Syst. 2018, 11, 151-166. [CrossRef]

23. Jefferies, D.; Ly, T.-A.; Göhlich, D. Energiebedarf verschiedener Klimatisierungssysteme für Elektro-Linienbusse. Dtsch. Kälte Klim. 2015, 20, 2-17.

24. Kiss, T.; Chaney, L.; Meyer, J. A New Automotive Air Conditioning System Simulation Tool Developed in MATLAB/Simulink. SAE Int. J. Passeng. Cars Mech. Syst. 2013, 6, 826-840. [CrossRef]

25. Kiss, T.; Lustbader, J.; Leighton, D. Modeling of an Electric Vehicle Thermal Management System in MATLAB/Simulink. In SAE Technical Paper Series; SAE 2015 World Congress \& Exhibition, APR. 21; SAE International400 Commonwealth Drive: Warrendale, PA, USA, 2015.

26. Lajunen, A. Energy Efficiency and Performance of Cabin Thermal Management in Electric Vehicles. In SAE Technical Paper Series; WCX $^{\mathrm{TM}}$ 17: SAE World Congress Experience, APR. 04; SAE International400 Commonwealth Drive: Warrendale, PA, USA, 2017.

27. Lee, H.; Hwang, Y.; Song, I.; Jang, K. Transient thermal model of passenger car's cabin and implementation to saturation cycle with alternative working fluids. Energy 2015, 90, 1859-1868. [CrossRef]

28. Nielsen, F.; Gullman, S.; Wallin, F.; Uddheim, Å.; Dalenbäck, J.-O. Simulation of Energy Used for Vehicle Interior Climate. SAE Int. J. Passeng. Cars Mech. Syst. 2015, 8, 1218-1234. [CrossRef]

29. Nielsen, F.; Uddheim, Å.; Dalenbäck, J.-O. Measurements of Energy Used for Vehicle Interior Climate. SAE Int. J. Passeng. Cars Mech. Syst. 2014, 7, 1404-1416. [CrossRef]

30. Sevilgen, G.; Bayram, H.; Kilic, M. 1D analysis of cool down simulation of vehicle HVAC system. Therm. Sci. 2020, 25, 1677-1687. [CrossRef] 
31. Song, B.; Kwon, J.; Kim, Y. Air Conditioning System Sizing for Pure Electric Vehicle. World Electr. Veh. J. 2015, 7, 407-413. [CrossRef]

32. Subiantoro, A.; Ooi, K.T.; Stimming, U. Energy saving measures for automotive air conditioning (AC) system in the tropics. In Proceedings of the 15th International Refrigeration and Air Conditioning Conference at Purdue, West Lafayette, IN, USA, 14-17 July 2014; Volume 2116, pp. 1-8.

33. Torregrosa-Jaime, B.; Payá, J.; Corberan, J. Design of Efficient Air-Conditioning Systems for Electric Vehicles. SAE Int. J. Altern. Powertrains 2013, 2, 291-303. [CrossRef]

34. Torregrosa-Jaime, B.; Bjurling, F.; Corberán, J.M.; Di Sciullo, F.; Payá, J. Transient thermal model of a vehicle's cabin validated under variable ambient conditions. Appl. Therm. Eng. 2015, 75, 45-53. [CrossRef]

35. Valentina, R.; Viehl, A.; Bringmann, O.; Rosenstiel, W. HVAC system modeling for range prediction of electric vehicles. In Proceedings of the 2014 IEEE Intelligent Vehicles Symposium (IV), Dearborn, MI, USA, 8-11 June 2014; pp. 1145-1150, ISBN 978-14799-3638-0.

36. Zhang, Q.; Canova, M. Lumped-Parameter Modeling of an Automotive Air Conditioning System for Energy Optimization and Management. In Proceedings of the ASME 6th Annual Dynamic Systems and Control Conference, Palo Alto, CA, USA, 21-23 October 2013; ASME: New York, NY, USA, 2014, ISBN 978-0-7918-5612-3.

37. Magna Powertrain, Engineering Center Steyr: KULI Software. Available online: https:/ / kuli.magna.com/ (accessed on 13 June 2021).

38. Nicoletti, L.; Romano, A.; König, A.; Schockenhoff, F.; Lienkamp, M. Parametric Modeling of Mass and Volume Effects for Battery Electric Vehicles, with Focus on the Wheel Components. WEVJ World Electr. Veh. J. 2020, 11, 63. [CrossRef]

39. Nicoletti, L.; Romano, A.; König, A.; Köhler, P.; Heinrich, M.; Lienkamp, M. An Estimation of the Lightweight Potential of Battery Electric Vehicles. Energies 2021, 14, 4655. [CrossRef]

40. König, A.; Nicoletti, L.; Kalt, S.; Muller, K.; Koch, A.; Lienkamp, M. An Open-Source Modular Quasi-Static Longitudinal Simulation for Full Electric Vehicles. In Proceedings of the 2020 Fifteenth International Conference on Ecological Vehicles and Renewable Energies (EVER), Monte-Carlo, Monaco, 10-12 September 2020; pp. 1-9, ISBN 978-1-7281-5641-5.

41. König, A.; Telschow, D.; Nicoletti, L.; Lienkamp, M. Package Planning of Autonomous Vehicle Concepts. Proc. Des. Soc. 2021, 1, 2369-2378. [CrossRef]

42. Nicoletti, L.; Köhler, P.; König, A.; Heinrich, M.; Lienkamp, M. Parametric Modelling of Weight and Volume Effects in Battery Electric Vehicles, with Focus on the Gearbox. Proc. Des. Soc. 2021, 1, 2389-2398. [CrossRef]

43. Kuptsov, V.; Fajri, P.; Trzynadlowski, A.; Zhang, G.; Magdaleno-Adame, S. Electromagnetic Analysis and Design Methodology for Permanent Magnet Motors Using MotorAnalysis-PM Software. Machines 2019, 7, 75. [CrossRef]

44. MotorXP-PM. Performance Analysis of the Tesla Model 3 Electric Motor using MotorXP-PM: Part 1. Available online: https: //motorxp.com/wp-content/uploads/mxp_analysis_TeslaModel3.pdf (accessed on 13 October 2021).

45. LMU_Fakultät für Meteologie. Zeitreihen-Oscar-von-Miller-Turm. Available online: https://www.meteo.physik.uni-muenche n.de/DokuWiki/doku.php?id=:wetter:garching:neu:zeitreihe (accessed on 24 September 2021).

46. König, A. HVAC-Consumption-Calculator. Available online: https://github.com/TUMFTM/HVAC-Consumption-Calculator (accessed on 8 November 2021).

47. Liu, Z.; Tan, H.; Kuang, X.; Hao, H.; Zhao, F. The Negative Impact of Vehicular Intelligence on Energy Consumption. J. Adv. Transp. 2019, 2019, 1521928. [CrossRef]

48. The International Council on Clean Transportation. Overview and Evaluation of Eco-Innovations in European Passenger Car $\mathrm{CO}_{2}$ Standards. Available online: https://theicct.org/sites/default/files/publications/EU_Eco_innovations_Briefing_20180712.pdf (accessed on 27 October 2021). 